MSC 74G55

\title{
About one approach to solving the inverse problem for parabolic equation*
}

\author{
A. P. Zhabko ${ }^{1}$, K. B. Nurtazina ${ }^{2}$, V. V. Provotorov ${ }^{3}$
}

${ }^{1}$ St. Petersburg State University, 7-9, Universitetskaya nab., St. Petersburg, 199034, Russian Federation

${ }^{2}$ L. N. Gumilyov Eurasian National University, 2, ul. Satpaeva, Nur-Sultan, 010008, Republic Kazakhstan

${ }^{3}$ Voronezh State University, 1, Universitetskaya pl., Voronezh, 394006, Russian Federation

For citation: Zhabko A. P., Nurtazina K. B., Provotorov V. V. About one approach to solving the inverse problem for parabolic equation. Vestnik of Saint Petersburg University. Applied Mathematics. Computer Science. Control Processes, 2019, vol. 15, iss. 3, pp. 323-336.

https://doi.org/10.21638/11702/spbu10.2019.303

Consider the problem of determining the coefficients in the differential equation of parabolic types and boundary conditions on the known sections of the solutions of the initial-boundary value problem. Used spectral approach based on spectral properties of the elliptic operator of the initial-boundary value problem and the methods of solving the inverse spectral problem of restoring the Sturm-Liouville operator on two sequences of the eigenvalues, that corresponding to two sets of boundary conditions. In the work presented sufficient conditions of determination of two sequences of the eigenvalues by two sets of boundary conditions and terms of the uniqueness of the solution of the inverse problem The paper considers the case where the initial-boundary value problem contains the specifics - the interval of change contains variable include a finite number of the points, where the differential equation is meaningless and replaced conditions agreement.

Keywords: parabolic system, inverse problem, the eigenvalues of boundary value problems, the poles of the analytical continuation of the Green's function.

Introduction. Many questions of mathematical physics lead to the need to determine the coefficients in a partial differential equation and the coefficients in the boundary conditions with known functionals from the solution of the corresponding initial-boundary value problem. In the case when the coefficients in a differential equation depend on the spatial variable, an explicit representation of the solution (for example, as an expansion in the eigenfunctions of the elliptic operator of the problem) makes it impossible to determine these coefficients. Therefore, other approaches are used, in particular, spectral, based on the spectral properties of the elliptic operator of the initial-boundary value problem and methods for solving the inverse spectral problem of recovering the Sturm-Liouville operator from two sequences of eigenvalues corresponding to two sets of boundary conditions (B. M. Levitan, M. G. Gasymov, I. S. Sargsyan, V. A. Yurko [17] and bibliography there). The sufficient conditions for determining of two sequences of eigenvalues from two sets of boundary conditions and the condition for the uniqueness of the solution of the inverse problem are presented below. Solving the inverse problem, we consider two cases - first, we will consider in detail the case of using the classical recovery problem of the Sturm-Liouville operator, then we will specify the way to solve the inverse problem with features determined by the presence of points in the spatial variable change

* This work was supported from the Ministry of education and science of the Republic Kazakhstan (projekt N AR05136197).

(C) Санкт-Петербургский государственный университет, 2019 
interval, where the differential equation is replaced by the matching conditions ([8, p. 33; 9, p. 31]).

Setting of a problem, the basic statement. Consider a uniform rod of length $\ell$, insulated from the sides and thin enough so that at any time the temperature at all points of the cross section can be considered the same. Denote by $T(x, t), x, t \in[0, \ell] \times[0, \infty)$, the function that determines the quantitative characteristic of the process of heat propagation in the rod, and by $a(x), b(x), x \in[0, \ell]$ the functions characterizing the internal properties of thermal phenomena (thermal conductivity, velocity characteristics, thermal resistance of the medium). Let the functions $T(x, t), a(x), b(x)$ satisfy the differential equation

$$
a(x) \frac{\partial T(x, t)}{\partial t}=\frac{\partial}{\partial x}\left(b(x) \frac{\partial T(x, t)}{\partial x}\right), \quad x \in(0, \ell), \quad t>0,
$$

that determines the law of heat transfer in the rod.

We divide the segment $[0, \ell]$ by dots $\xi_{j}(j=0,1, \ldots, N, N+1): 0=\xi_{0}<\xi_{1}<$ $\ldots<\xi_{N}<\xi_{N+1}=\ell$ and we denote: $(0, \ell)_{\xi}=\bigcup_{j=0}^{N}\left(\xi_{j}, \xi_{j+1}\right)\left([0, \ell]\right.$ is the closure $\left.(0, \ell)_{\xi}\right)$, $\Omega_{\infty}=(0, \ell)_{\xi} \times(0, \infty), \bar{\Omega}_{\infty}=[0, \ell] \times[0, \infty]$. Let functions $T(x, t), x, t \in[0, \ell] \times[0, \infty), a(x)$, $b(x), x \in[0, \ell]$ be connected by a differential equation

$$
a(x) \frac{\partial T(x, t)}{\partial t}=\frac{\partial}{\partial x}\left(b(x) \frac{\partial T(x, t)}{\partial x}\right), \quad x \in \Omega_{\infty},
$$

and the agreement conditions in points $\xi_{j}$ :

$$
\begin{gathered}
T\left(\xi_{j}^{-}, t\right)=T\left(\xi_{j}^{+}, t\right), \quad b\left(\xi_{j}^{+}\right) \frac{\partial T\left(\xi_{j}^{+}, t\right)}{\partial x}-b\left(\xi_{j}^{-}\right) \frac{\partial T\left(\xi_{j}^{-}, t\right)}{\partial x}=m_{j} T\left(\xi_{j}, t\right) \\
(j=1,2, \ldots, N),
\end{gathered}
$$

here

$$
\begin{aligned}
& T\left(\xi^{+}, t\right)=\lim _{\epsilon \rightarrow 0} T(\xi+\epsilon, t), \quad \frac{\partial T\left(\xi^{+}, t\right)}{\partial x}=\lim _{\epsilon \rightarrow 0} \frac{\partial T(\xi+\epsilon, t)}{\partial x}, \\
& T\left(\xi^{-}, t\right)=\lim _{\epsilon \rightarrow 0} T(\xi-\epsilon, t), \quad \frac{\partial T\left(\xi^{-}, t\right)}{\partial x}=\lim _{\epsilon \rightarrow 0} \frac{\partial T(\xi-\epsilon, t)}{\partial x} .
\end{aligned}
$$

Relations (2), (3) are called the differential equation on $(0, \ell)$ with singularities at the points $\xi_{j}(j=1, \ldots, N)$. In applied heat transfer problems, equation (2), (3) describes the process of heat distribution with external control devices (such can perform the functions of control actions on the process), the peripheral components of which are located at the points $\xi_{j}, j=0,1, \ldots, N, M+1$ (see, for example, [10, p. 10]). Physical phenomena in extreme situations with phase transition temperatures and diffusion processes in materials of complex structures such as polymers are studied using integro-differential equations with memory. The inverse problem for such a process is solved, for example, in [11], where the boundary control method $[12,13]$ is applied. It is based on deep connections between controllability and identifiability of dynamical systems.

The agreement conditions (2) describe the distribution of heat in the neighbourhood of the points that the peripheral components of control devices put on and represent generalized Kirchhoff relations - a jump in heat fluxes with proportionality coefficients in adjacent parts of a heat-conducting material (rod).

To set the initial-boundary value problems we introduce the initial 


$$
T(x, 0)=0, \quad x \in[0, \ell]
$$

and boundary conditions

$$
\frac{\partial T\left(0^{+}, t\right)}{\partial x}=\alpha\left(T\left(0^{+}, t\right)-T_{0}(t)\right), \frac{\partial T\left(\ell^{-}, t\right)}{\partial x}=-\beta\left(T\left(\ell^{-}, t\right)-T_{\ell}(t)\right), \quad t>0 .
$$

To simplify the presentation, the initial condition (4) is assumed to be homogeneous. The boundary conditions (5) are determined by the functions $T_{0}(t), T_{\ell}(t), t>0$, and constant $\alpha, \beta$. In this case, the simplest case - the linear one - of the absence of the convective effect of the thermal process is studied.

Further we assume that $T(x, t)$ from the class $C^{1,0}\left(\bar{\Omega}_{\infty}\right) \cap C^{2,1}\left(\Omega_{\infty}\right), a(x), b(x)$ positive on $[0, \ell]$ and $a(x) \in \bigcup_{j=0}^{N} C\left[\xi_{j}, \xi_{j+1}\right], b(x) \in \bigcup_{j=0}^{N} C^{1}\left[\xi_{j}, \xi_{j+1}\right]$; functions $T_{0}(t), T_{\ell}(t)$ continuous on $[0, \infty)$, such that there exist constants $C_{1}>0, C_{2}$ for them, and there are relations

$$
\left|T_{0}(t)\right| \leqslant C_{1} e^{C_{2} t}, \quad\left|T_{\ell}(t)\right| \leqslant C_{1} e^{C_{2} t}
$$

The initial-boundary value problem formed by the differential system (1), (4), (5) has a unique solution [9, p. 75], the unique solvability of system (2)-(5) was established in $[8$, p. $33 ; 10$, p. 10], where a problem with singularities is interpreted as a problem with distributed parameters on a geometric graph.

Solution $T(x, t)$ of problem (1), (4), (5) or (2)-(5) with given functions $a(x), b(x)$, $T_{0}(t), T_{\ell}(t)$ and constant $\alpha, \beta$ will be called the solution of the direct problem (1), (4), (5) or $(2)-(5)$. By the inverse problem (1), (4), (5) or (2)-(5), we understand the problem of recovering functions $a(x), b(x)$ and constants $\alpha, \beta$ according to information about solution $T(x, t)$.

Let, further, the parameter $\alpha$ in the boundary conditions (5) takes two different values $\alpha_{1}$ and $\alpha_{2}$. Let us denote by $T_{k}(x, t)$ solving the initial-boundary value problem (1), (4), (5) or (2)-(5) for $\alpha=\alpha_{k}$ for each fixed $k=1,2$, and by $f_{k}(t)=T_{k}\left(x_{*}, t\right), t>0$, the solution cross section $T_{k}(x, t), k=1,2$, at the point $x=x_{*}$ (for system (2)-(5) the point $x_{*}$ can coincide with one of $\left.\xi_{j}, j=\overline{1, N}\right)$.

Definition. Let the functions $b(x), T_{0}(t), T_{\ell}(t)$ and $f_{k}(t) \in C^{1}[0, \infty)(k=1,2)$ are given. The set $\left\{T_{k}(x, t), a(x), \alpha_{k}, \beta(k=1,2)\right\}$ is called the solution of the inverse problem (1), (4), (5) or $(2)-(5)$, if:

1) $T_{k}(x, t) \in C\left(\bar{\Omega}_{\infty}\right) \cap C^{2,1}\left(\Omega_{\infty}\right), T_{k}\left(x_{*}, t\right)=f_{k}(t)$;

2) $\alpha, \beta$ are constants, $\alpha^{2}+\beta^{2}>0$;

3) for each fixed $k=1,2$ function $T_{k}(x, t), a(x), b(x), T_{0}(t), T_{\ell}(t)$ and constants $\alpha_{k}$, $\beta$, satisfy the problem (1), (4), (5) or (2)-(5).

As it follows from the definition, to solve the inverse problem (1), (4), (5) or (2)-(5) means: for given $b(x), T_{0}(t), T_{\ell}(t)$ and two sets of functions $f_{k}(t)=T_{k}\left(x_{*}, t\right)(k=1,2)$, that meet the corresponding boundary conditions (5) and $x=0$ with $\alpha=\alpha_{k}(k=1,2)$, recover functions $T_{k}(x, t), a(x)$ and constants $\alpha_{k}(k=1,2), \beta$. The inverse problem (1), $(4),(5)$ or $(2)-(5)$ in the case when the function $a(x)$ is known, but $b(x)$ to be determined, is put in a similar way.

We prove the uniqueness of the solution of the inverse problem (1), (4), (5) or (2)-(5), based on the results of $[1,4,5,7]$ on the recovering of the Sturm-Liouville operator from two spectrum corresponding to two different boundary conditions at a point $x=0$.

We give equations (1) and (2) using the substitution 


$$
\begin{gathered}
z(x)=\frac{1}{L} \int_{0}^{x}\left(\frac{a(\tau)}{b(\tau)}\right)^{\frac{1}{2}} d \tau, \quad L=\frac{1}{\pi} \int_{0}^{\ell}\left(\frac{a(\tau)}{b(\tau)}\right)^{\frac{1}{2}} d \tau, \\
U(z, t)=(a(x) b(x))^{\frac{1}{4}} T(x, t)
\end{gathered}
$$

(replacement $\{x, T(x, t)\} \Rightarrow\{z, U(z, t)\})$ to mind

$$
L^{2} \frac{\partial U(z, t)}{\partial t}-\frac{\partial^{2} U(z, t)}{\partial z^{2}}-q(z) U(z, t), \quad x \in(0, \ell), \quad t>0,
$$

and

$$
L^{2} \frac{\partial U(z, t)}{\partial t}-\frac{\partial^{2} U(z, t)}{\partial z^{2}}-q(z) U(z, t), \quad z \in\left(\zeta_{j}, \zeta_{j+1}\right)(j=0,1, \ldots, N), \quad t>0,
$$

respectively, where $q(z)=\frac{\theta^{\prime \prime}(z)}{\theta(z)}, \theta(z)=(a(x) b(x))^{\frac{1}{4}}, \zeta_{j}=z\left(\xi_{j}\right)(j=\overline{1, N}), \zeta_{0}=0$, $z\left(\xi_{N+1}\right)=\pi$. The agreement conditions (3) take the form

$$
\begin{gathered}
U\left(\zeta_{j}^{-}, t\right)=U\left(\zeta_{j}^{+}, t\right), \quad \frac{\partial U\left(\zeta_{j}^{+}, t\right)}{\partial x}-\frac{\partial U\left(\zeta_{j}^{-}, t\right)}{\partial x}=m_{j} U\left(\zeta_{j}, t\right) \\
(j=1,2, \ldots, N)
\end{gathered}
$$

the initial condition (4) does not change its form:

$$
U(z, 0)=0, \quad z \in[0, \pi],
$$

and the boundary conditions (5) are converted to

$$
\frac{\partial U\left(0^{+}, t\right)}{\partial z}-h U\left(0^{+}, t\right)=-\frac{\alpha L}{\theta(0)} T_{0}(t), \quad \frac{\partial U\left(\pi^{-}, t\right)}{\partial x}+H U\left(\pi^{-}, t\right)=\frac{\beta L}{\theta(\pi)} T_{\ell}(t),
$$

where $h=\left(\alpha L+\theta(0) \theta^{\prime}(0)\right) / \theta^{2}(0), H=\left(\beta L+\theta(\pi) \theta^{\prime}(\pi)\right) / \theta^{2}(\pi)$. In this case, the interval $[0, \ell]$ is converted to $[0, \pi]$.

I. Let us dwell on the analysis of the inverse problem (1), (4), (5), reduced to the form $(6),(9),(10)$. The initial boundary value problem (6), (9), (10) generates a spectral problem

$$
\begin{gathered}
-y^{\prime \prime}+q(z) y=\mu y, \quad z \in(0, \pi), \\
y^{\prime}\left(0^{+}\right)-h y\left(0^{+}\right)=0, \quad y^{\prime}\left(\pi^{-}\right)+H y\left(\pi^{-}\right)=0 .
\end{gathered}
$$

Let in the first relation (5) $\alpha=\alpha_{k}, k=1,2$, then in (12) $h=h_{k}(k=1,2)$. Let us also denote the sets of eigenvalues $\left\{\mu_{n}^{1}\right\}_{n=0}^{\infty}$ and $\left\{\mu_{n}^{2}\right\}_{n=0}^{\infty}$ of the boundary value problems (11), (12) for $h=h_{1}$ and $h=h_{2}$ (the Sturm-Liouville problem (11), (12) has only a discrete spectrum [7]).

There is an inverse Sturm-Liouville problem [1, 4, 7] based on the following fact: the spectral function $\rho(\mu)$ of the operator generated by the boundary value problem (11), (12) uniquely determines this problem (i. e. $\left.q(z), h_{1}, h_{2}, H\right)$, and in the case of a regular Sturm-Liouville problem, the spectral function is determined by two sequences of numbers $\left\{\mu_{n}^{1}\right\}_{n=0}^{\infty}$ and $\left\{\mu_{n}^{2}\right\}_{n=0}^{\infty}$ :

$$
\rho(\mu)=\sum_{\mu_{n}^{1}<\mu} \frac{1}{\omega_{n}}, \quad \omega_{n}=\frac{h_{2}-h_{1}}{\mu_{n}^{2}-\mu_{n}^{1}} \prod_{i=0(i \neq n)} \frac{\mu_{i}^{1}-\mu_{n}^{1}}{\mu_{i}^{2}-\mu_{i}^{1}}
$$

here $\omega_{n}(n=0,1, \ldots)$ are the norms of the eigenfunctions $y\left(z, \mu_{n}^{1}\right)$ (normalization factors) corresponding to the eigenvalues $\mu_{n}^{1}$. Numerical sequences $\left\{\mu_{n}^{1}\right\}_{n=0}^{\infty}$ (or $\left.\left\{\mu_{n}^{2}\right\}_{n=0}^{\infty}\right)$ and 
$\left\{\omega_{n}\right\}_{n=0}^{\infty}$ are called the spectral characteristics of the Sturm-Liouville operator of the boundary value problem (11), (12).

We can specify the necessary and sufficient conditions for the two sequences of real numbers $\left\{\mu_{n}^{1}\right\}_{n=0}^{\infty}$ and $\left\{\mu_{n}^{2}\right\}_{n=0}^{\infty}$ to be two spectrums of the boundary value problem (11), (12) $\left(h=h_{k}, k=1,2\right)$, corresponding to the same equation (11) with a continuous potential $q(z)$, i. e. solve Sturm-Liouville problem (11), (12). These conditions are as follows $[1,4]$ :

1) numbers $\mu_{n}^{1}$ and $\mu_{n}^{2}(n=0,1, \ldots)$ are alternated,

2) asymptotic formulas are valid for them

$$
\sqrt{\mu_{n}^{k}}=n+\frac{a_{0}^{k}}{n}+O\left(\frac{1}{n}\right), \quad k=1,2,
$$

where $a_{0}^{1} \neq a_{0}^{2}$.

The main result. The solution of the inverse problem (1), (4), (5) will consist of three stages:

1) determination of eigenvalues $\mu_{n}^{1}, \mu_{n}^{2}(n=0,1, \ldots)$ of problem $(11),(12)\left(h=h_{k}\right.$, $k=1,2)$,

2) definition of potential $q(z)$ in equation (11) and constants $h_{k}(k=1,2), H$ in boundary conditions (12),

$3)$ the definition of the combination $\left\{T_{k}(x, t), a(x), \alpha_{k}, \beta(k=1,2)\right\}$.

Remark 1. In the case when the function $a(x)$ is known, but $b(x)$ to be determined, the set is determined $\left\{T_{k}(x, t), b(x), \alpha_{k}, \beta(k=1,2)\right\}$.

In the future, along with problem (1), (4), (5), we consider its Laplace transform (for the possibility of applying the Laplace transform in this case, see [14, p. 234]).

The Fourier method for problem (1), (4), (5) allows us to construct a solution when the boundary conditions (5) are inhomogeneous. Under some conditions that are not burdensome in applications, relatively $\alpha$ and $\beta(\beta-\alpha-\alpha \beta \ell \neq 0)$ the solution $T(x, t)$ can be represented as $[9$, p. 473]

$$
\begin{gathered}
T(x, t)=\left(c_{1} x+c_{2}\right) T_{0}(t)+\left(c_{3} x+c_{4}\right) T_{\ell}(t)+ \\
+\sum_{n=0}^{\infty}\left(W_{n}(t) e^{-\gamma_{n} t}+\int_{0}^{t} V_{n}(\tau) e^{-\gamma_{n}(t-\tau)} d \tau\right) u_{n}(x),
\end{gathered}
$$

where $c_{1}, c_{2}, c_{3}, c_{4}$ are fixed constants, $\gamma_{n}, u_{n}(x)(n=0,1, \ldots)$ are eigenvalues and orthonormal eigenfunctions of the boundary value problem

$$
\begin{gathered}
-\frac{d}{d x}\left(b(x) \frac{u}{d x}\right)=\gamma a(x) u, \quad x \in(0, \ell), \\
b\left(\xi_{j}^{+}\right) \frac{d u\left(0^{+}\right)}{\partial x}-\alpha u\left(0^{+}\right)=0, \quad b\left(\xi_{j}^{-}\right) \frac{d u\left(\ell^{-}\right)}{\partial x}+\beta u\left(\ell^{-}\right)=0,
\end{gathered}
$$

$W_{n}(t), V_{n}(t)(n=0,1, \ldots)$ are the Fourier coefficients of functions

$$
\begin{aligned}
& W(x, t)=\left(c_{1} x+c_{2}\right) T_{0}(t)+\left(c_{3} x+c_{4}\right) T_{\ell}(t), \\
& V(x, t)=-a(x) \frac{\partial W(x, t)}{\partial t}+\frac{\partial}{\partial x}\left(b(x) \frac{\partial W(x, t)}{\partial x}\right),
\end{aligned}
$$

when decomposing them in a Fourier series in a system $\left\{u_{n}(x)\right\}_{n=0}^{\infty}$.

The representation of the solution $T(x, t)$ in the form of a series (14) confirms the validity of applying the Laplace transform to problem (1), (4), (5) in the right half-plane $\mathbb{P}_{+}=\left\{p: \operatorname{Re} p \geqslant \nu, \nu>-\gamma_{0}\right\}$, if the constant $C_{2}$ in the description of functions $T_{0}(t)$, $T_{\ell}(t)$ is smaller than $\nu$. Below, the image of the Laplace function $\phi$ will be indicated $\phi^{*}$. 
The initial-boundary value problem (1), (4), (5) transformed according to Laplace in the half-plane $\mathbb{P}_{+}$takes the form

$$
\begin{gathered}
\frac{d}{d x}\left(b(x) \frac{d T^{*}(x, p)}{d x}\right)=p a(x) T^{*}(x, p), \quad x \in(0, \ell), \\
\frac{\partial T^{*}\left(0^{+}, p\right)}{\partial x}=\alpha\left(T^{*}\left(0^{+}, p\right)-T_{0}^{*}(p)\right), \frac{\partial T^{*}\left(\ell^{-}, p\right)}{\partial x}=-\beta\left(T^{*}\left(\ell^{-}, p\right)-T_{\ell}^{*}(p)\right) .
\end{gathered}
$$

We introduce the following notation: $\mathbb{M}=\left\{\mu_{m}\right\}$ is the set of eigenvalues $\mu_{m}$ of the Sturm-Liouville problem (11), (12), $\boldsymbol{\Lambda}=\left\{L^{2} \lambda_{m}\right\}$ is the set of poles $\lambda_{m}$ of the analytic continuation of an element $\frac{f^{*}(-p)}{T_{0}^{*}(-p)}, f^{*}(p)=T^{*}\left(x_{*}, p\right), x_{*} \in(0, \ell)$, along the real half-line $\{p: \operatorname{Re} p \geqslant-\nu, \operatorname{Im} \nu=0\}, T(x, t)$ is the solution of initial-boundary value problem (1), (4), (5).

Theorem 1. If $\alpha \neq 0$ and $T_{\ell}(t) \equiv 0$ then the inclusion $\boldsymbol{\Lambda} \subseteq \mathbb{M}$ is correct.

$\mathrm{P}$ r o o f. The boundary value problem (15), (16) in the half-plane $\mathbb{P}_{+}$has no eigenvalues and, therefore, is uniquely solvable for $p \in \mathbb{P}_{+}$. Let us denote by $G(x, s, p)$ the Green function of the problem (15), (16). Then

$$
T^{*}(x, p)=\alpha G(x, 0, p) T_{0}^{*}(p)+\beta G(x, \ell, p) T_{\ell}^{*}(p) .
$$

The Green function is a meromorphic function of a parameter $p$ on the entire complex plane, its poles (all poles of the Green function are simple) can only be the eigenvalues $\eta_{n}$ $(n=0,1, \ldots)$ of problem $(15),(16)$ (for $\left.T_{0}^{*}(p) \equiv T_{\ell}^{*}(p) \equiv 0\right)$.

We denote $\lambda_{n}=-\eta_{n}$ the poles of the function $G(x, s,-p)$. Obviously $\lambda_{n}$ belong to the real semi-axis $\{\operatorname{Re} p \geqslant-\nu, \operatorname{Im} p=0\}$. Given the replacement $\{x, T(x, t)\} \Rightarrow\{z, U(z, t)\}$ (i. e. $\left.z(x)=\frac{1}{L} \int_{0}^{x}\left(\frac{a(\tau)}{b(\tau)}\right)^{\frac{1}{2}} d \tau, L=\frac{1}{\pi} \int_{0}^{\ell}\left(\frac{a(\tau)}{b(\tau)}\right)^{\frac{1}{2}} d \tau\right)$, we obtain

$$
\mu_{n}=L^{2} \lambda_{n}
$$

Since $T_{\ell}(t) \equiv 0$, the statement of the theorem obviously follows from (17) and the relation $G\left(x_{*}, 0, p\right)=\frac{T^{*}\left(x_{*}, p\right)}{\alpha T_{0}^{*}(p)}=\frac{f^{*}(p)}{\alpha T_{0}^{*}(p)}$.

Remark 2. If $\alpha=0$, then $T_{\ell}(t) \neq 0$, and the eigenvalues $\mu_{n}$ are determined from (18), where $\lambda_{n}$ are the poles of the analytic continuation $\frac{f^{*}(-p)}{T_{\ell}^{*}(-p)}$.

Remark 3. If in the first relation (4) we replace $\alpha$ with $\alpha_{k}(k=1,2)$, then the eigenvalues $\mu_{n}^{k}(k=1,2)$ of problem (9)-(11) with $h=h_{k}(k=1,2)$ are associated by means of (18) with the poles $\lambda_{n}^{k}$ of the analytic continuation of an element $f_{k}^{*}(-p) / T_{0}^{*}(-p)$ $(k=1,2)$ or of an element $f_{k}^{*}(-p) / T_{\ell}^{*}(-p)(k=1,2)$, if any of $\alpha_{k}$ equals zero.

Remark 4. If you only need to define a function $a(x)$ or $b(x)$, then the assumption $T_{\ell}(t) \equiv 0$ can always be considered complete.

We indicate a method of analytic continuation of elements defined in the half-plane by the ratio of Laplace integrals. Moreover, some ideas were borrowed from [15].

Suppose now that $T_{\ell}(t) \neq 0$, then and $T_{0}(t) \neq 0$. Let be $g_{1}(p)=\frac{\beta T_{\ell}^{*}(p)}{\alpha T_{0}^{*}(p)}, g_{2}(p)=$ $\frac{f^{*}(p)}{\alpha T_{0}^{*}(p)}, G_{0}(p)=G\left(x_{*}, 0, p\right), G_{\ell}(p)=G\left(x_{*}, \ell, p\right)$. In these notation, the relation (17) when $x=\xi_{1}$ takes the form

$$
g_{2}(p)=G_{0}(p)+g_{1}(p) G_{\ell}(p) .
$$

We represent the function $g_{2}(p)$ as a power series in a neighborhood of an arbitrary real point $p_{1} \in \mathbb{P}_{+}$:

$$
g_{2}(p)=\sum_{j=0}^{\infty} g_{2}^{0, j}\left(p-p_{1}\right)^{j}, \quad g_{2}^{0, j}=\frac{1}{j !} g_{2}^{(j)}\left(p_{1}\right)
$$


According to the Fabry relation theorem, if on the boundary of the circle of convergence of series (20) there is one singular point, namely, a simple pole $\bar{p}$, then

$$
\bar{p}=p_{1}+\lim _{j \rightarrow \infty} \frac{g_{2}^{0, j}}{g_{2}^{0, j+1}} .
$$

Since in the half-plane $\mathbb{P}_{+}$to the right of the point $\nu$, the Green function $G(x, s, p)$ has no singular points, then $\bar{p}=-\lambda_{0}$ its first pole, and therefore $-\lambda_{0}=p_{1}+\lim _{j \rightarrow \infty} \frac{g_{2}^{0, j}}{g_{2}^{0, j+1}}$. Singling out the main member in (20), we get a series

$$
\left(1+\frac{p-p_{1}}{\lambda_{0}+p_{1}}\right) \sum_{j=0}^{\infty} g_{2}^{0, j}\left(p-p_{1}\right)^{j}=g_{2}^{0,0}-\sum_{j=0}^{\infty} g_{2}^{1, j}\left(p-p_{1}\right)^{j}, \quad g_{2}^{1, j+1}=\frac{-g_{2}^{0, j}}{\lambda_{0}+p_{1}}-g_{2}^{0, j+1}
$$

with the same center at a point $p_{1}$ as $(20)$, but with a radius of convergence equal to the distance from the point $p_{1}$ to the second pole $-\lambda_{1}$ of the Green function $G(x, s, p)$. From here we find $-\lambda_{1}$ :

$$
-\lambda_{1}=p_{1}+\lim _{j \rightarrow \infty} \frac{g_{2}^{1, j}}{g_{2}^{1, j+1}}, \quad g_{2}^{1, j+1}=-\frac{g_{2}^{0, j}}{\lambda_{0}+p_{1}}-g_{2}^{0, j+1}
$$

and so on. Thus we obtained (when $g_{1}(p)=0$, see (19)).

Theorem 2. Let the conditions of Theorem 1 were fulfilled, then the eigenvalues $\mu_{n}$ $(n=0,1, \ldots$,$) of the boundary value problem (11), (12) are determined from the relations:$

$$
\begin{gathered}
-\lambda_{0}=p_{1}+\lim _{j \rightarrow \infty} \frac{g_{2}^{0, j}}{g_{2}^{0, j+1}}, \quad g_{2}^{0, j}=\frac{1}{j !} g_{2}^{(j)}\left(p_{1}\right), \\
-\lambda_{n}=p_{1}+\lim _{j \rightarrow \infty} \frac{g_{2}^{n, j}}{g_{2}^{n, j+1}}, \quad g_{2}^{n, j+1}=-\frac{g_{2}^{n-1, j}}{\lambda_{n-1}+p_{1}}-g_{2}^{n-1, j+1}, \quad n=1,2, \ldots, \\
\mu_{n}=L^{2} \lambda_{n}, \quad n=0,1, \ldots
\end{gathered}
$$

where $p_{1} \in \mathbb{P}_{+}$is an arbitrary real number.

Remark 5. If exists

$$
\lim _{j \rightarrow \infty} \frac{f^{*(j+1)}(p)}{(j+1) f^{*(j)}(p)}=q
$$

for arbitrary real $p \in \mathbb{P}_{+}$and series

$$
\Phi(p)=\sum_{m=0}^{\infty} \frac{(-1)^{m}}{m !} T_{0}^{*(m)}(p)\left(p+\lambda_{1}\right)^{m}
$$

(representation of the function $T_{0}^{*}(p)$ as a power series) converges, and $\Phi(p) \neq 0$, then $p+\lambda_{1}=-\frac{1}{q}$.

Indeed, from the statements of Theorem 2 it follows that

$$
-\frac{1}{\lambda_{0}+p}=\lim _{j \rightarrow \infty} \frac{g_{2}^{*(j+1)}(p)}{(j+1) g_{2}^{*(j)}(p)} .
$$

We denote this limit by $q_{1}$ and show that $q=q_{1}$. Use equality

$$
\begin{gathered}
\frac{1}{\alpha_{k}} f_{k}^{*(j)}(p)= \\
=T_{0}^{*}(p) g_{2}^{(j)}(p)+\ldots+\frac{j(j-1) \ldots(j-m+1)}{m !} T_{0}^{*(m)}(p) g_{2}^{(j-m)}(p)+\ldots+T_{0}^{*(j)}(p) g_{2}(p),
\end{gathered}
$$


from which it follows:

$$
\begin{gathered}
\frac{1}{\alpha_{k}} \frac{f_{k}^{*(j)}(p)}{g_{2}^{(j)}(p)}= \\
=T_{0}^{*}(p)+\ldots+\frac{j(j-1) \ldots(j-m+1)}{m !} T_{0}^{*(m)}(p) \frac{g_{2}^{(j-m)}(p)}{g_{2}^{(j)}(p)}+\ldots+T_{0}^{*(j)}(p) \frac{g_{2}(p)}{g_{2}^{(j)}(p)} .
\end{gathered}
$$

Passing to the limit at the left and right when $j \rightarrow \infty$, we find $\lim _{j \rightarrow \infty} \frac{f_{k}^{*(j)}(p)}{g_{2}^{(j)}(p)}=\Phi(p)$. So as $\Phi(p) \neq 0$ and $\Phi(p) \neq \infty$ then

$$
q_{1}=\lim _{j \rightarrow \infty} \frac{g_{2}^{(j+1)}(p)}{f_{k}^{*(j+1)}(p)} \cdot \frac{f_{k}^{*(j+1)}(p)}{(j+1) f_{k}^{*(j)}(p)} \cdot \frac{f_{k}^{*(j)}(p)}{g_{2}^{(j)}(p)}=q
$$

that required to prove.

We note the obvious benefit of the above statement: it allows us to find the first pole on the basis more simply than (21), the calculated limit in Remark 5 .

The statements of Theorems 1 and 2 for finding the eigenvalues $\mu_{n}, n=0,1, \ldots$, of the boundary value problem (11), (12) make it possible to determine the poles of the Green function $G(x, s, p)$ with fixed first two arguments. In this connection, it may happen that the set of eigenvalues $\boldsymbol{\Lambda}$ does not coincide with the set of these poles $\mathbb{M}$ (therefore, in Theorem 1, only the inclusion $\boldsymbol{\Lambda} \subseteq \mathbb{M}$ takes place). However, in applications for some cases, from a priori considerations it is possible to obtain information about the choice of a variable fixation point $x$ (everywhere above is a point $x=x_{*}$ or any $\xi_{j}, j=\overline{1, N}$ ) so that at least the first few eigenvalues $\mu_{n}$ will determine (see (18)) the first poles $\lambda_{n}$. Therefore, we can assume that the choice of the point of fixation of the variable $x$ is such that the sets $\boldsymbol{\Lambda}$ and $\mathbb{M}$ coincide.

Theorem 3. Two sequences of numbers $\left\{\mu_{n}^{k}\right\}_{n=0}^{\infty}, k=1,2$, uniquely determine the norms $\omega_{n}=\int_{0}^{\pi} y^{2}\left(z, \mu_{n}^{1}\right) d z$ of the eigenfunctions $y\left(z, \mu_{n}^{1}\right)$ of the boundary value problem (11), (12) (normalization numbers, see the second ratio (13)):

$$
\omega_{n}=\pi \frac{a_{0}^{2}-a_{0}^{1}}{\mu_{n}^{2}-\mu_{n}^{1}} \prod_{i=0(i \neq n)} \frac{\mu_{i}^{1}-\mu_{n}^{1}}{\mu_{i}^{2}-\mu_{i}^{1}},
$$

absolutely continuous on $[0, \pi]$ function $q(z)$ and constant $h_{1}, h_{2}, H$. In addition $h_{2}-h_{1}=$ $\pi\left(a_{0}^{2}-a_{0}^{1}\right)$.

A detailed proof of the theorem is given in [1].

Denote by $y(z, \mu)$ solution of the equation (11) with initial conditions $y(0, \mu)=1$, $y^{\prime}(0, \mu)=h_{1}$. Then the solution to this problem is represented as

$$
y(z, \mu)=\cos \sqrt{\mu} z+\int_{0}^{z} K(z, s) \cos \sqrt{\mu} \tau d \tau .
$$

Such a relation connecting the solution $y(z, \mu)$ of equation (11) and the solution $\cos \sqrt{\mu} z$ of the equation $-y^{\prime \prime}=\mu y$ with the initial conditions $y(0, \mu)=1, y^{\prime}(0, \mu)=0$, is called the transformation operator with the kernel $K(z, s)$. Knowledge of the kernel $K(z, s)$ determines the function $y(z, \mu)$, and the function $q(z)$ is thereby determined since $\mu-$ $q(z)=-y^{\prime \prime}(z, \mu) / y(z, \mu)$, as well as constants $h$ and $H$ from the boundary conditions (12). Thus, the inverse problem (11), (12) is reduced to the definition of a function $K(z, s)$ that satisfies the integral equation

$$
F(z, s)+K(z, s)=\int_{0}^{z} F(\tau, s) K(\tau, s) d \tau=0, \quad 0 \leqslant s \leqslant z \leqslant \pi,
$$


where

$$
F(z, s)=\frac{1}{\pi}+\sum_{n=0}^{\infty}\left(\frac{1}{\omega_{n}} \cos \sqrt{\mu_{n}} z \cos \sqrt{\mu_{n}} s-\frac{2}{\pi} \cos n z \cos n s\right),
$$

$\mu_{n}(n=0,1, \ldots)$ are eigenvalues of the boundary value problem $(11),(12)$.

Theorem 4. The inverse problem (1), (4), (5) cannot have two different solutions.

P r o o f. Suppose the opposite: there are two solutions to the inverse problem (1), (4), (5), that is, two sets $\left\{T_{k}^{i}(x, t), a^{i}(x), \alpha_{k}^{i}, \beta^{i}(k=1,2)\right\}, i=1,2$. Hence, these solutions correspond to two functions $q^{i}(z)$ and two sets of constants $h_{k}^{i}(k=1,2), H^{i}, i=1,2$. For each fixed $i=1,2$ function $q^{i}(z)$ and constant $h_{k}^{i}(k=1,2), H^{i}$, correspond to the sequence of eigenvalues $\left\{\mu_{n}^{k, i}\right\}_{n=0}^{\infty}(k=1,2), i=1,2$. On the other hand, the analytic continuation of the elements $f_{k}^{*}(-p) / T_{0}^{*}(-p)\left(f_{k}(t)=f_{k}^{i}(t), k=1,2, i=1,2\right)$ uniquely determine the poles $\lambda_{n}^{k}(k=1,2)$, and therefore, uniquely determine the eigenvalues $\mu_{n}^{k}$ $(k=1,2)$. This means that for $i=1,2 \mu_{n}^{k, i}=\mu_{n}^{k}(k=1,2)$. It follows from Theorem 3 above that the sequences $\left\{\mu_{n}^{k}\right\}_{n=0}^{\infty}(k=1,2)$ uniquely determine the function $q(z)$ on the interval $[0, \pi]$ and the numbers $h_{k}(k=1,2), H$. Therefore, for $i=1,2 q^{i}(z) \equiv q(z)$, $h_{k}^{i}=h_{k}(k=1,2), H^{i}=H$.

Do the replacement $\{x, T(x, t)\} \Rightarrow\{z, U(z, t)\}$ in the opposite direction: $\{z, U(z$, $t)\} \Rightarrow\{x, T(x, t)\}$, then

$$
a(x) b(x)=\theta^{4}(z(x)), \quad x \in[0, \ell],
$$

where $\theta(z)$ is the solution of a boundary value problem

$$
\begin{gathered}
\theta^{\prime \prime}(z)=q(z) \theta(z), \quad z \in[0, \pi], \\
\theta(0)=(a(0) b(0))^{\frac{1}{4}}, \quad \theta(\pi)=(a(\ell) b(\ell))^{\frac{1}{4}},
\end{gathered}
$$

but $z(x)$ is the solution of the Cauchy problem

$$
z^{\prime}(x)=\frac{1}{L} \frac{\theta^{2}(z)}{b(x)}, \quad x \in[0, \ell], \quad z(0)=0 .
$$

From the assumptions made about the functions $a(x)$ and $b(x)$ it follows that the boundary value problem $(23),(24)$ is uniquely solvable. The constants $\alpha_{k}(k=1,2)$ and $\beta$ are uniquely determined from the relations

$$
\alpha_{k}=\frac{1}{L}\left(h_{k} \theta^{2}(0)-\theta(0) \theta^{\prime}(0)\right), \quad \beta=\frac{1}{L}\left(H \theta^{2}(\pi)+\theta(\pi) \theta^{\prime}(\pi)\right) .
$$

By the found $a(x), \alpha_{k}(k=1,2)$ and $\beta$, the function $T_{k}(x, t)$ for each fixed $k=1,2$ is uniquely determined by solving the direct problem $(1),(4),(5)$. It is clear that the resulting set $\left\{T_{k}(x, t), a(x), \alpha_{k}, \beta(k=1,2)\right\}$ satisfies the definition of the solution of the inverse problem (1), (4), (5) and for $i=1,2, T_{k}^{i}(x, t) \equiv T_{k}(x, t), a^{i}(x) \equiv a(x), \alpha_{k}^{i}=\alpha_{k}(k=1,2)$, $\beta^{i}=\beta$. The theorem is proved.

Remark 6. The assertion of Theorem 4 remains true also in the case when the function $b(x)$ is unknown, but the relation connecting $a(x)$ and $b(x)$ is known: $a(x)=$ $\Phi(b(x))$, where $\Phi(\cdot)>0$ is twice continuously differentiable by its argument. If the system of equations (22), (25) has a unique solution $b(x)>0, b(x) \in C^{2}[0, \ell]$ and $z(x) \in C^{1}[0, \ell]$ then the solution to the inverse problem $(1),(4),(5)$ is unique. The function $a(x)$ is determined from $a(x)=\Phi(b(x))$.

The proof of Theorem 4 implies an algorithm for constructing a solution, i. e. set $\left\{T_{k}(x, t), a(x), \alpha_{k}, \beta(k=1,2)\right\}$, inverse problem (1), (4), (5). The initial data for the inverse problem (1), (4), (5) are: 
a) the functions entering the boundary conditions (5) $T_{0}(t)$ and $T_{\ell}(t), t>0$;

b) the sections $f_{1}(t), f_{2}(t), t>0$, at the point $x=x_{*}$ of solutions of the initialboundary value problem (1), (4), (5) under two different $\left(\alpha=\alpha_{k}, k=1,2, \alpha_{1} \neq \alpha_{2}\right)$ boundary conditions (5) at a point $x=0$;

c) function $b(x)$.

Remark 7. In the case when the function $a(x)$ is known (see clause $(c)$ ), the set should be determined the set $\left\{T_{k}(x, t), b(x), \alpha_{k}(k=1,2), \beta\right\}$.

The algorithm for constructing the solution of the inverse problem (1), (4), (5):

1) there are poles $\lambda_{n}^{k}, n=0,1, \ldots(k=1,2)$, of analytic continuation of elements $\frac{f_{k}^{*}(-p)}{T_{0}^{*}(-p)}, f_{k}(t)=f_{k}(t)(k=1,2)-$ statements of Theorems 1 and 2 ; is built

2) on two sequences of eigenvalues $\mu_{n}^{k}\left(\mu_{n}^{k}=L^{2} \lambda_{n}^{k}\right), n=0,1, \ldots(k=1,2)$, the function

$$
F(z, s)=\frac{1}{\pi}+\sum_{n=0}^{\infty}\left(\frac{1}{\omega_{n}} \cos \sqrt{\mu_{n}^{1}} z \cos \sqrt{\mu_{n}^{1}} s-\frac{2}{\pi} \cos n z \cos n s\right)
$$

(here $\left.\omega_{n}=\pi \frac{a_{0}^{2}-a_{0}^{1}}{\mu_{n}^{2}-\mu_{n}^{1}} \prod_{i=0(i \neq n)} \frac{\mu_{i}^{1}-\mu_{n}^{1}}{\mu_{i}^{2}-\mu_{i}^{1}}\right)$ and the solution $K(z, s)$ of the integral equation is determined

$$
F(z, s)+K(z, s)=\int_{0}^{z} F(\tau, s) K(\tau, s) d \tau=0, \quad 0 \leqslant s \leqslant z \leqslant \pi
$$

3) the potential $q(z)$ and constants $h_{k}(k=1,2), H$ are determined from the function $K(z, s)$ found

$$
\begin{gathered}
q(z)=2 \frac{d K(z, z)}{d z}, \quad h_{1}=K(0,0)=-F(0,0), h_{2}=K(0,0)+\pi\left(a_{0}^{2}-a_{0}^{1}\right), \\
H=-\frac{y^{\prime}\left(\pi, \mu_{0}^{1}\right)}{y\left(\pi, \mu_{0}^{1}\right)}=-\frac{y^{\prime}\left(\pi, \mu_{1}^{1}\right)}{y\left(\pi, \mu_{1}^{1}\right)}, \ldots,-\frac{y^{\prime}\left(\pi, \mu_{n}^{1}\right)}{y\left(\pi, \mu_{n}^{1}\right)}, \ldots,
\end{gathered}
$$

where $y\left(\pi, \mu_{n}^{1}\right)=\cos \sqrt{\mu_{n}^{1}} z+\int_{0}^{z} K(\tau, s) \sqrt{\mu_{n}^{1}} \tau d \tau, n=0,1, \ldots$;

4) functions $T_{k}(x, t)(k=1,2)$ are defined as solutions of direct problems (1), (4), (5) with those found $a(x), \alpha_{k}(k=1,2), \beta$, and, therefore, the set $\left\{T_{k}(x, t), a(x), \alpha_{k}, \beta(k=\right.$ $1,2)$ is determined.

II. Next, we consider the inverse problem with singularities (2)-(5), reduced to the form (7)-(10). The initial-boundary problem (7)-(10) corresponds to the spectral problem

$$
\begin{gathered}
-y^{\prime \prime}+q(z) y=\mu y, \quad z \in\left(\zeta_{j}, \zeta_{j+1}\right), \quad j=0,1, \ldots, N, \\
y\left(\zeta_{j}^{-}, t\right)=y\left(\zeta_{j}^{+}, t\right), \quad y^{\prime}\left(\zeta_{j}^{+}, t\right)-y^{\prime}\left(\zeta_{j}^{-}, t\right)=m_{j} y\left(\zeta_{j}, t\right), \quad j=1,2, \ldots, N, \\
y^{\prime}\left(0^{+}\right)-h y\left(0^{+}\right)=0, \quad y^{\prime}\left(\pi^{-}\right)+H y\left(\pi^{-}\right)=0 .
\end{gathered}
$$

In $[8$, p. 33] it is shown that the spectrum of the boundary value problem (26)-(28) is discrete. If, as above, in the first relation (5) we put $\alpha=\alpha_{k}, k=1,2$, then in (28) $h=h_{k}$ $(k=1,2)$ and we get two sets of eigenvalues, knowledge of which determines the spectral function of the operator generated by the boundary value problem (26)-(28) (constant $h$ one of $h_{1}$ or $h_{2}$ ) and further potential $q(z)$ and constant $h_{1}, h_{2}, H$.

Assuming that the Laplace transform is applicable to problem (2)-(5) (section $\mathbf{I}$ ), statements similar to those presented in Theorems 1 and 2 are applicable to determine the 
eigenvalues of the boundary value problem (26)-(28). As a point $x_{*}$ where the sections of solutions $f_{k}(t)=T_{k}\left(x_{*}, t\right)(k=1,2)$ of problem $(2)-(5)$ are known, we can take any of the points $\xi_{j}, j=\overline{1, N}$. Connection is established (transformation operator with the kernel $K(z, s))$

$$
y(z, \mu)=y^{0}(z, \mu)+\int_{0}^{z} K(z, s) y^{0}(\tau, \mu) d \tau
$$

between the solution $y(z, \mu), z \in(0, \pi)$ equations $(26),(27)$, satisfying the initial conditions $y(0, \mu)=1, y^{\prime}(0, \mu)=h$ and the solution

$$
y^{0}(z, \mu)=y_{j}^{0}(z, \mu), \quad z \in\left[\zeta_{j}, \zeta_{j+1}\right](j=0,1, \ldots, N)
$$

equations $(26)$ (under $q(z) \equiv 0),(27)$ with initial conditions $y(0, \mu)=1, y^{\prime}(0, \mu)=0$; here

$$
\begin{gathered}
y_{0}^{0}(z, \mu)=\cos \sqrt{\mu} z \\
y_{1}^{0}(z, \mu)=\frac{1}{\sqrt{\mu}}\left(\sqrt{\mu}-m_{1} \cos \sqrt{\mu} \zeta_{1}^{+} \sin \sqrt{\mu} \zeta_{1}^{+}\right) \cos \sqrt{\mu} \zeta+ \\
+\frac{1}{\sqrt{\mu}} m_{1} \cos ^{2} \sqrt{\mu} \zeta_{1}^{+} \sin \sqrt{\mu} \zeta
\end{gathered}
$$

and under $j=2,3, \ldots, N$

$$
\begin{gathered}
y_{j}^{0}(z, \mu)=\left(\cos \sqrt{\mu} \zeta_{j}^{+} y_{j-1}^{0}\left(\zeta_{j}^{-}, \mu\right)-\frac{1}{\sqrt{\mu}} y_{j-1}^{0,1}\left(\zeta_{j}^{-}, \mu\right) \sin \sqrt{\mu} \zeta_{j}^{+}\right) \cos \sqrt{\mu} \zeta+ \\
+\left(\sin \sqrt{\mu} \zeta_{j}^{+} y_{j-1}^{0}\left(\zeta_{j}^{-}, \mu\right)-\frac{1}{\sqrt{\mu}} y_{j-1}^{0,1}\left(\zeta_{j}^{-}, \mu\right) \cos \sqrt{\mu} \zeta_{j}^{+}\right) \sin \sqrt{\mu} \zeta
\end{gathered}
$$

where $y_{j-1}^{0,1}\left(\zeta_{j}^{-}, \mu\right)=\frac{d y_{j-1}^{0}\left(\zeta_{j}^{-}, \mu\right)}{d z}+m_{2} y_{j-1}^{0}\left(\zeta_{j}^{-}, \mu\right)$.

Knowledge of the kernel $K(z, s)$ determines the solution of the inverse problem (26)(28), that is, the function $q(z)$ and the constants $h, H$. The further reasoning is almost word for word in Section $\mathbf{I}$.

Conclusion. The paper presents a new approach in determining the eigenvalues of the elliptic operator of the initial-boundary value problem (including peculiarities) for an equation of parabolic type over the cross section for solving this equation at the internal point of the spatial coordinate change (statements of Theorems 1, 2). This made it possible to use the classical results of recovering the Sturm-Liouville operator from spectral characteristics [1-3, 7] and the subsequent solution of the inverse problem for a parabolic equation. Note that the results obtained complement (and in a certain sense, develop) the ideas and research presented in [16-18] when analyzing the questions of solvability of multidimensional systems. Recent results in the direction of analyzing evolutionary systems in network-like regions (see [19-21]) allow partial use of the results of this work in constructing stabilizing control actions in complex articulations. It should also be noted that the approaches to the analysis of dynamic systems presented in [22-26] allow partial use of the results of this work, namely, the widespread use of operational calculus techniques.

\section{References}

1. Gasymov M. G., Levitan B. M. Opredelenie differencial'nogo operatora po dvum spektram [Definition of a differential operator from two spectrums]. Uspekhi matematicheskikh nauk [Russian Mathematical Surveys], 1964, vol. 19, iss. 2 (116), pp. 3-63. (In Russian)

2. Levitan B. M., Sargsyan I. S. Vvedenie v spektral'nuyu teoriyu [Introduction to spectral theory]. Moscow, Nauka Publ., 1970, 672 p. (In Russian) 
3. Levitan B. M. Teoriya operatorov obobschennogo sdviga [Theory of generalized shift operators]. Moscow, Nauka Publ., 1973, 312 p. (In Russian)

4. Yurko V. A. Obratnaya zadacha dlya differentsial'nyh uravneniy s osobennost'yu [The inverse problem for differential equations with singularity]. Differentsial'niye uravnenia [Differential equations], 1992, vol. 28, iss. 8, pp. 1355-1362. (In Russian)

5. Yurko V. A. O vosstanovlenii differencial'nyh operatorov Shturma-Liuvillya s osobennost'yu vnutri intervala [On the reconstruction of the Sturm-Liouville differential operators with a feature inside the interval]. Matematicheskie zametki [Mathematical Notes], 1998, vol. 64, iss. 1, pp. 143-156. (In Russian)

6. Yurko V. A. O kraevyh zadachah s usloviyami razryva vnutri intervala [On boundary value problems with discontinuity conditions inside the interval]. Differentsial'niye uravnenia [Differential equations], 2000, vol. 36, iss. 8, pp. 1139-1140. (In Russian)

7. Yurko V. A. Vvedenie $v$ teoriyu obratnih spektral'nih zadach [Introduction to the theory of inverse spectral problems]. Moscow, Fizmatlit Publ., 2007, 384 p. (In Russian)

8. Provotorov V. V., Volkova A. S. Nachal'no-kraevie zadachi s raspredelennimi parametrami na grafe [Initial boundary value problems with distributed parameters on the graph]. Voronezh, Nauchnaya kniga Publ., 2014, 188 p. (In Russian)

9. Vladimirov V.S. Uravneniya matematicheskoi fiziki [Equations of mathematical physics]. Moscow, Nauka Publ., 1971, 512 p. (In Russian)

10. Provotorov V. V. Sobstvennye funktsii kraevyh zadach na grafah i prilozheniya [Eigenfunctions of boundary value problems on graphs and applications]. Voronezh, Nauchnaya kniga Publ., 2008,247 p. (In Russian)

11. Avdonin S., Murzabekova G., Nurtazina K. Source identification for the differential equation with memory. Trends in Mathematics. Research Perspective. Birkhäuser, Springer International Publishing Switzerland, 2017, pp. 111-120.

12. Avdonin S., Kurasov P. Inverse problems for quantum trees. Inverse Problems Imag., 2008, vol. 2, iss. 1. pp. 3973-3991.

13. Avdonin S., Bell J., Nurtazina K. Determining distributed parameters in a neuronal cable model on a tree graph. Mathematic Methods in the Applied Sciences, 2017, vol. 40, iss. 11, pp. 3973-3991.

14. Ladyzhenskaya O. A. Kraevye zadachi matematicheskoi fiziki [Boundary value problems of mathematical physics]. Moscow, Nauka Publ., 1973, 407 p. (In Russian)

15. Bieberbach L. Analiticheskoe prodolzenie [Analytical continuation]. Moscow, Nauka Publ., 1967, 240 p. (In Russian)

16. Karelin V. V., Bure V. M., Svirkin M. V. Obobchennaja model rasprostranenija informacii v neprerivnom vremeni [The generalized model of information dissemination in continuous time]. Vestnik of Saint Petersburg University. Applied Mathematics. Computer Science. Control Processes, 2017, vol. 13, iss. 1, pp. 74-80. https://doi.org/10.21638/11701/spbu 10.2017.107 (In Russian)

17. Aliseiko A. N. Matricy Lyapunova dlya klassa sistem s eksponencial'nym yadrom [Lyapunov matrices for a class of systems with an exponential core]. Vestnik of Saint Petersburg University. Applied Mathematics. Computer Science. Control Processes, 2017, vol. 13, iss. 3, pp. 228-240. https://doi.org/10.21638/11701/spbu 10.2017.301 (In Russian)

18. Avdonin S., Edward J. Exact controllability for string with attached masses. SIAM J. Control Optim, 2018, vol. 56, iss. 2, pp. 945-980. https://doi.org/10.1137/15M1029333

19. Provotorov V. V., Ryazhskikh V. I., Gnilitskaya Yu. A. Unique weak solvability of a nonlinear initial boundary value problem with distributed parameters in a netlike region. Vestnik of Saint Petersburg University. Applied Mathematics. Computer Science. Control Processes, 2017, vol. 13, iss. 3, pp. $264-277$. https://doi.org/10.21638/11701/spbu10.2017.304

20. Zhabko A. P., Tikhomirov O. G., Chizhova O. N. On stabilization of a class of systems with time proportional delay. Vestnik of Saint Petersburg University. Applied Mathematics. Computer Science. Control Processes, 2018, vol. 14, iss. 2, pp. 165-172. https://doi.org/10.21638/11702/spbu10.2018.209

21. Provotorov V. V., Provotorova E. N. Sintez optimal'nogo granichnogo upravlenija parabolicheskoi sistemy s zapazdyvaniem i raspredelennymi parametrami na grafe [Synthesis of optimal boundary control of parabolic systems with delay and distributed parameters on the graph]. Vestnik of Saint Petersburg University. Applied Mathematics. Computer Science. Control Processes, 2017, vol. 13, iss. 2, pp. 209-224. https://doi.org/10.21638/11701/spbu10.2017.207 (In Russian)

22. Provotorov V. V., Provotorova E. N. Optimal control of the linearized Navier-Stokes system in a netlike domain. Vestnik of Saint Petersburg University. Applied Mathematics. Computer Science. Control Processes, 2017, vol. 13, iss. 4, pp. 428-441. https://doi.org/10.21638/11701/spbu10.2017.409

23. Ponomarev A. A. Approksimaciya obratnoi svyazi v regulyatore "predictor-corrector" yavnoi funkcii [Approximation of feedback in the "predictor-corrector" regulator by an explicit function]. Vestnik of Saint Petersburg University. Applied Mathematics. Computer Science. Control Processes, 2017, vol. 13, iss. 2, pp. 193-208. https://doi.org/10.21638/11701/spbu 10.2017.206 (In Russian) 
24. Kuptsova S. E., Kuptsov S. Yu., Stepenko N. A. On the limiting behavior of a time-delay system's solution. Vestnik of Saint Petersburg University. Applied Mathematics. Computer Science. Control Processes, 2018, vol. 14, iss. 2, pp. 173-182. https://doi.org/10.21638/11702/spbu10.2018.2010

25. Iliashenko O., Krasnov S., Sergeev S. Calculation of high-rise construction limitations for nonresident housing fund in megacities. E3S Web of Conferences. International Scientific Conference on High-Rise Construction, HRC, 2018, vol. 33, iss. 6, paper no. 030062017, pp. 03006.

26. Artemov M. A., Baranovskii E. S., Zhabko A. P., Provotorov V. V. On a 3D model of nonisothermal flows in a pipeline network. Journal of Physics: Conference Series, 2019, vol. 1203, Article ID 012094. https://doi.org/10.1088/1742-6596/1203/1/012094

Received: May 15, 2019.

Accepted: June 06, 2019.

Author's information:

Aleksei P. Zhabko - Dr. Sci. in Physics and Mathematics, Professor; zhabko.apmath.spbu@mail.ru

Karlygash B. Nurtazina - PhD in Physics and Mathematics, Associate Professor; knurtazina@mail.ru

Vyacheslav V. Provotorov - Dr. Sci. in Physics and Mathematics, Professor; wwprov@mail.ru

\section{Об одном подходе к решению обратной задачи для параболического уравнения*}

А. П. Жабко ${ }^{1}$, К. Б. Нуртазина ${ }^{2}$, В. В. Провоторов ${ }^{3}$

${ }^{1}$ Санкт-Петербургский государственный университет, Российская Федерация, 199034, Санкт-Петербург, Университетская наб., 7-9

2 Евразийский национальный университет имени Л. Н. Гумилева, Республика Казахстан, 010008, Нур-Султан, ул. Сатбаева, 2

3 Воронежский государственный университет, Российская Федерация, 394006, Воронеж, Университетская пл., 1

Для цитирования: Zhabko A. P., Nurtazina K. B., Provotorov V. V. About one approach to solving the inverse problem for parabolic equation // Вестник Санкт-Петербургского университета. Прикладная математика. Информатика. Процессы управления. 2019. Т. 15. Вып. 3. C. 323-336. https://doi.org/10.21638/11702/spbu10.2019.303 (In English)

Работа посвящена решению задачи определения коэффициентов в линейном дифференциальном уравнении параболического типа и краевых условиях. При этом предполагаются известными значения решения начально-краевой задачи в некоторой фиксированной точке интервала изменения пространственной переменной и во все моменты времени (сечение решения). Использован спектральный подход, основанный на спектральных свойствах эллиптического оператора начально-краевой задачи и методах решения обратной спектральной задачи восстановления оператора Штурма-Лиувилля по двум последовательностям собственных значений, соответствующим двум наборам граничных условий (при этом используются классические результаты Б. М. Левитана, М. Г. Гасымова, И. С. Саргсяна, В. А. Юрко). В связи с этим основные усилия авторов были направлены на решение задачи определения спектральных характеристик оператора Штурма-Лиувилля. Применяется преобразование Лапласа к начально-краевой задаче в правой полуплоскости изменения параметра преобразования (здесь используется свойство положительности дискретного спектра симметричного вполне непрерывного эллиптического оператора). Устанавливается мероморфность по этому параметру функции Грина полученной краевой задачи, ее полюсами являются собственные

* Работа выполнена при финансовой поддержке Министерства образования и науки Республики Казахстан (проект № AP05136197). 
значения краевой задачи. Представлены достаточные условия определения двух последовательностей собственных значений по двум наборам граничных условий и условия единственности решения обратной задачи. В работе рассмотрен случай, когда начальнокраевая задача содержит особенности - интервал изменения пространственной переменной содержит конечное число точек, в которых дифференциальное уравнение теряет смысл и заменяется условиями согласования. Полученные результаты используются при неразрушающем контроле в теплофизических процессах.

Ключевые слова: параболическая система, обратная задача, собственные значения краевых задач, полюсы аналитического продолжения функции Грина.

Контактная информация:

Жабко Алексей Петрович - д-р физ.-мат. наук, проф.; zhabko.apmath.spbu@mail.ru

Нуртазина Карльгаш Бегахметовна - канд. физ.-мат. наук, доц.; knurtazina@mail.ru

Провоторов Вячеслав Васильевич - д-р физ.-мат. наук, проф.; wwprov@mail.ru 